\title{
Article \\ Molecular and Clinical Features of Hospital Admissions in Patients with Thoracic Malignancies on Immune Checkpoint Inhibitors
}

\author{
Dan Zhao ${ }^{1}$, Haiqing Li ${ }^{2,3}$, Isa Mambetsariev ${ }^{1}$, Chen Chen ${ }^{4}$, Rebecca Pharaon ${ }^{1}$, Jeremy Fricke ${ }^{1}$, Angel R. Baroz ${ }^{1}$, \\ Prakash Kulkarni ${ }^{1}$, Yan Xing ${ }^{1}$, Erminia Massarelli ${ }^{1}{ }^{(D,}$, Marianna Koczywas ${ }^{1}$, Karen L. Reckamp ${ }^{1,5}$, \\ Kim Margolin ${ }^{1}$ and Ravi Salgia ${ }^{1, * \mathbb{D}}$ \\ 1 Department of Medical Oncology and Therapeutics Research, City of Hope National Medical Center, \\ Duarte, CA 91010-3000, USA; DZhao3@mdanderson.org (D.Z.); Imambetsariev@coh.org (I.M.); \\ rpharaon@coh.org (R.P.); jfricke@coh.org (J.F.); abaroz@coh.org (A.R.B.); pkulkarni@coh.org (P.K.); \\ yxing@coh.org (Y.X.); emassarelli@coh.org (E.M.); MKoczywas@coh.org (M.K.); \\ Karen.Reckamp@cshs.org (K.L.R.); kmargolin@coh.org (K.M.) \\ 2 Integrative Genomics Core, Beckman Research Institute, City of Hope Medical Center, \\ Duarte, CA 91010-3000, USA; hali@coh.org \\ 3 Department of Computational \& Quantitative Medicine, Beckman Research Institute, \\ City of Hope National Medical Center, Duarte, CA 91010-3000, USA \\ 4 Applied AI and Data Science, City of Hope National Medical Center, Duarte, CA 91010-3000, USA; \\ chechen@coh.org \\ check for \\ updates \\ 5 Department of Medicine, Cedars-Sinai Medical Center, Los Angeles, CA 91010-3000, USA \\ * Correspondence: rsalgia@coh.org; Tel.: +1-626-218-3712; Fax: +1-626-471-7322
}

Citation: Zhao, D.; Li, H.; Mambetsariev, I.; Chen, C.; Pharaon, R.; Fricke, J.; Baroz, A.R.; Kulkarni, P.; Xing, Y.; Massarelli, E.; et al. Molecular and Clinical Features of Hospital Admissions in Patients with Thoracic Malignancies on Immune Checkpoint Inhibitors. Cancers 2021, 13, 2653. https://doi.org/10.3390/ cancers 13112653

Academic Editor: Steven G. Gray

Received: 30 April 2021

Accepted: 25 May 2021

Published: 28 May 2021

Publisher's Note: MDPI stays neutral with regard to jurisdictional claims in published maps and institutional affiliations.

Copyright: (c) 2021 by the authors. Licensee MDPI, Basel, Switzerland. This article is an open access article distributed under the terms and conditions of the Creative Commons Attribution (CC BY) license (https:// creativecommons.org/licenses/by/ $4.0 /)$
Simple Summary: Lung cancer immunotherapy has many complications and hospitalizations that often occur in non-small cell lung cancer (NSCLC) while on immunotherapy due to adverse events or other factors. The molecular and clinical profiles of these patients are often not well-defined, and the aim of our retrospective study is to better understand these clinical and molecular features. We evaluated a cohort of 90 stage IV thoracic malignancy patients who had hospital admissions after treatment with immune checkpoint inhibitors. We identified a relationship between immune-related adverse events (irAEs) and molecular markers that showed unique survival outcomes, as well as a significant overall survival improvement in patients who required discontinuation or interruption of immunotherapy due to irAEs.

Abstract: Lung cancer patients undergoing systemic treatment with immune checkpoint inhibitors (ICIs) can lead to severe immune-related adverse events (irAEs) that may warrant immediate hospitalization. Patients with thoracic malignancies hospitalized at City of Hope while undergoing treatment with ICIs were identified. Pathology and available next-generation sequencing (NGS) data, including the programmed death-ligand 1 (PD-L1) status and clinical information, including hospitalizations, invasive procedures, and the occurrence of irAEs, were collected. Unpaired T-tests, Chi-square/Fisher's exact test, and logistic regression were used to analyze our cohort. The overall survival (OS) was calculated and compared using univariate and multivariate COX models. Ninety patients with stage IV lung cancer were admitted after ICI treatment. Of those patients, 28 (31.1\%) had documented irAEs. Genomic analyses showed an enrichment of $L R P 1 B$ mutations ( $n=5 / 6$ vs. $n=7 / 26,83.3 \%$ vs. $26.9 \%$; odds ratio (OR) (95\% confidence interval (CI): $13.5(1.7-166.1) ; p<0.05)$ and MLL3 mutations ( $n=4 / 6,66.7 \%$ vs. $n=5 / 26,19.2 \%$; OR (95\% CI): $8.4(1.3-49.3), p<0.05)$ in patients with irAE occurrences. Patients with somatic genomic alterations (GAs) in MET (median OS of 2.7 vs. 7.2 months; HR (95\% CI): 3.1 (0.57-17.1); $p<0.05)$ or FANCA (median OS of 3.0 vs. 12.4 months; HR (95\% CI): $3.1(0.70-13.8) ; p<0.05)$ demonstrated a significantly shorter OS. Patients with irAEs showed a trend toward improved OS (median OS 16.4 vs. 6.8 months, $p=0.19$ ) compared to hospitalized patients without documented irAEs. Lung cancer patients who required treatment discontinuance or interruption due to irAEs $(n=19)$ had significantly longer OS (median OS 18.5 vs. 6.2 months; HR (95\% CI): 0.47 (0.28-0.79); $p<0.05)$. Our results showed a significant survival benefit in lung cancer 
patients hospitalized due to irAEs that necessitated a treatment interruption. Patients with positive somatic GAs in MET and FANCA were associated with significantly worse OS compared to patients with negative GAs.

Keywords: lung cancer; checkpoint inhibitors; immune-related adverse events (irAEs); admissions; genomic alterations; next-generation sequencing; overall survival

\section{Introduction}

Immune checkpoint inhibitors (ICIs) targeting programmed cell death protein 1 (PD-1), programmed death-ligand 1 (PD-L1), and cytotoxic T-lymphocyte-associated antigen 4 (CTLA-4) have transformed the landscape of lung cancer treatment. Pembrolizumab, an anti-PD-1 monoclonal antibody, was approved by the US Food and Drug Administration (FDA) as a monotherapy first-line treatment of metastatic non-small cell lung cancer (NSCLC) with PD-L1 expression $\geq 1$, and in combination with chemotherapy regardless of PD-L1 status [1-4].

Atezolizumab and durvalumab, anti-PD-L1 monoclonal antibodies, were approved as a first-line treatment in combination with chemotherapy for small cell lung cancer (SCLC) [5-7]. Nivolumab, an anti-PD-1 monoclonal antibody, and ipilimumab, an antiCTLA-4 monoclonal antibody, with or without chemotherapy, were also recently approved for first-line treatment of metastatic lung cancer [8-12]. Durvalumab was approved for consolidation therapy after chemoradiation in unresectable stage III NSCLC, leading to further investigation of ICIs in the neoadjuvant setting [13,14].

However, hospital admission during treatment is common in cancer patients undergoing systemic treatment. Distinct toxicity profiles and immune-related adverse events (irAEs) due to ICIs have been widely reported, including skin reactions, thyroid disorders, pneumonitis, colitis, hepatitis, hypophysitis, and myocarditis $[15,16]$. Other severe adverse events not related to ICIs can emerge as well during treatment and lead to hospitalization. In a meta-analysis of 35 clinical trials involving ICIs, irAEs of grade 3 and above were reported in $14 \%$ of patients treated with monotherapy ICIs, $34 \%$ with anti-CTLA- 4 antibodies, $46 \%$ with combination ICI-chemotherapy, and 55\% with ICIs combinations [17].

Fatality rates were observed in $0.36 \%$ of patients treated with PD- 1 inhibitors, $0.38 \%$ with PD-L1 inhibitors, $1.08 \%$ with CTLA-4 inhibitors, and $1.23 \%$ with combination therapy of PD-1/PD-L1 and CTLA-4 inhibitors [18]. Patients who expired during PD-1/PD-L1 inhibitor treatment had severe complications, including pneumonitis (35\%), hepatitis (22\%), and neurotoxicities (15\%); a majority of the deaths observed in the CTLA- 4 treatment group were due to severe colitis (70\%) [18].

Several prominent oncologic societies, such as the National Comprehensive Cancer Network (NCCN), American Society of Clinical Oncology (ASCO), and Society for Immunotherapy of Cancer (SITC), have published guidelines on the management of irAEs in the standard clinical setting. However, irAE management in patients who require hospitalization and are steroids-refractory remains problematic [19-21]. The characterization of clinical features regarding irAEs and non-irAEs in hospitalized patients may facilitate the understanding and management of toxicities in this setting.

Previous studies have described associations between several tumor genomic features and the tumor response to ICIs. Notably, a poor tumor response was reported in patients on ICIs with molecular alterations in EGFR or MET [22-24]. In addition to a poor response, the development of severe irAEs (especially within 3 months) has been described in a retrospective analysis of EGFR mutated NSCLC patients $(15 \% ; 6 / 41)$ treated with ICIs followed by osimertinib, although the underlying mechanisms are still poorly understood [25]. However, the development of irAEs has not been established as a predictive marker in measuring responsiveness to ICIs. 
The clinical characterization of irAEs and full assessment of genomic data is necessary to optimize the patient selection criteria for ICI treatment, understand the underlying mechanisms of irAE development, and develop novel strategies to avoid irAEs while maintaining the anti-tumor efficacy [26]. In our retrospective analysis, we collected clinical and molecular information on 90 patients diagnosed with thoracic malignancies who received ICI treatment and were subsequently hospitalized in order to characterize irAE and nonirAE development, evaluate the management of irAEs, and analyze the survival outcomes.

\section{Materials and Methods}

\subsection{Patients}

Patients with metastatic thoracic malignancies who were hospitalized after receiving ICI treatment (pembrolizumab, nivolumab, atezolizumab, and ipilimumab/nivolumab) in different treatment settings, including standard of care, compassionate use, and clinical trials at City of Hope were reviewed. Ninety patients with histologies, including SCLC, NSCLC, and other thoracic malignancies were identified. Demographic, clinical, and pathological information was collected with approval by the City of Hope institutional review board (IRB \#18529). The overall survival (OS) was measured from the start of the ICI treatment to the date of death and calculated, if available, at the study time point. The data cutoff date was 8 November 2018.

\subsection{Clinical and Molecular Information Collection}

Tumor genomic alterations (GAs) were extracted from the available clinical data on next-generation sequencing (NGS) via several platforms, including FoundationOne (Foundation Medicine, Cambridge, MA, USA), Caris (Caris Life Sciences, Phoenix, AZ, USA), Paradigm (Paradigm Diagnostics, Phoenix, AZ, USA), Guardant360 (Guardant, Redwood City, CA, USA), NeoGenomics (NeoGenomics Laboratories, Fort Myers, FL, USA), and City of Hope gene sequencing panels. The PD-L1 (22C3) expression by immunohistochemistry was reported as the tumor proportion score (TPS), which is defined as the percentage of viable tumor cells showing partial or complete membrane staining of $\geq 1 \%$ relative to all viable tumor cells present in the sample.

Negative PD-L1 expression was defined as $<1 \%$ of viable tumor cells showing membranous staining. The tumor mutational burden (TMB) was reported and categorized as low ( $\leq 5$ Muts $/ \mathrm{Mb}$ ), intermediate (6-19 Muts $/ \mathrm{Mb})$, or high $(\geq 20 \mathrm{Muts} / \mathrm{Mb})$ by Foundation Medicine. Somatic GAs were sorted by the detected positive rate of GAs among all tested patients (the number of tested patients for each gene varied due to different gene panels in the testing platforms). IrAEs were defined as treatment-related toxicities documented by the admitting physician or primary oncologist and independently confirmed by another physician who reviewed the patient medical charts, including the laboratory, imaging, and pathological evidence.

The severity of irAEs was documented from grade 1 to 5 as per the National Institute of Health Common Terminology Criteria for Adverse Events (CTCAE), version 4.03. Clinical information, such as lines of therapy; the length of stay (LOS) in hospital; the status of metastatic disease in the brain; the therapy regimen of ICIs; the management of irAEs, including invasive, diagnostic, and therapeutic procedures; and any interruption or discontinuation of ICIs due to irAEs was also collected.

\subsection{Statistical Analysis}

First, the association of clinical and molecular features with the OS was analyzed using the univariate Cox proportional hazards model. Based on the results of the univariate analysis, clinically and biologically relevant features with statistical significance (cutoff $p$-value of 0.05 with the number of patients, $n \geq 5$ ) were selected for the multivariate Cox proportional hazards model. TMB was categorized by Foundation Medicine molecular testing reports. PD-L1 expression was categorized as negative $(<1 \%)$, and positive (grouped as $1-49 \%$ and $\geq 50 \%$ ). 
We used the Kaplan-Meier method and log-rank test to estimate the OS, and we compared the survival curves, respectively. The chi-square test, Fisher's exact test, and logistic regression were used for comparison between patient groups (i.e., patients who had irAEs vs. patients who did not have irAEs). Statistical analyses and data visualization were performed using GraphPad Prism 8 (GraphPad Software, Version 8, Graphpad Holdings, LLC, San Diego, CA, USA) and R (version 3.6.2, R Foundation for Statistical Computing, Vienna, Austria) [27]. All tests were two-sided, and $p<0.05$ was considered statistically significant.

\section{Results}

\subsection{Patients Characteristics}

Ninety patients with stage IV thoracic malignancies underwent admission to the City of Hope after ICI treatment. The dates of ICI treatment initiation were between 6 May 2015, and 6 August 2018. Of those admitted, 28 (31.1\%) had documented irAEs, and 62 (68.9\%) did not experience any irAEs (Table 1$)$. The most common irAE was pneumonitis $(n=10$, $11.1 \%)$ followed by adrenal insufficiency $(n=4,4.4 \%)$, hypothyroidism $(n=4,4.4 \%)$, colitis $(n=4,4.4 \%)$, liver injury $(n=3,3.3 \%)$, nephritis $(n=2,2.2 \%)$, infection $(n=2,2.2 \%)$, rash $(n=2,2.2 \%)$, heart failure $(n=1,1.1 \%)$, pancreatitis $(n=1,1.1 \%)$, diabetic ketone acidosis $(n=1,1.1 \%)$, and arthralgia $(n=1,1.1 \%)$. Seven patients $(7.8 \%)$ experienced multiple irAEs.

Table 1. List of irAEs.

\begin{tabular}{cc}
\hline IrAEs & No (\%) \\
\hline Pneumonitis & $10(11.1 \%)$ \\
Adrenal insufficiency & $4(4.4 \%)$ \\
Hypothyroidism & $4(4.4 \%)$ \\
Colitis & $4(4.4 \%)$ \\
Liver injury & $3(3.3 \%)$ \\
Nephritis & $2(2.2 \%)$ \\
Heart failure & $1(1.1 \%)$ \\
Pancreatitis & $1(1.1 \%)$ \\
Diabetic ketone acidosis & $1(1.1 \%)$ \\
Arthralgia & $1(1.1 \%)$ \\
Rash & $2(2.2 \%)$ \\
Other $/$ Infection & $2(2.2 \%)$ \\
Multiple irAEs & $7(7.8 \%)$ \\
Total patients with irAEs & $28(31.1 \%)$ \\
\hline
\end{tabular}

190 patients had hospital admissions during ICI treatment.

The baseline characteristics of the 90 patients are summarized in Table 2. Disease histologies included 63 patients (70\%) with adenocarcinoma, 14 (15.6\%) with squamous cell lung cancer, 5 (5.6\%) with SCLC, and 8 (8.9\%) with other types (1 poorly differentiated tumor including NSCLC, not otherwise specified (NSCLC-NOS), 1 large cell lung cancer, 1 lung atypical carcinoid, 1 adenosquamous tumor, 1 mixed large cell with neuroendocrine tumor, 1 small cell transformed lung adenocarcinoma, 1 mixed adenocarcinoma with large cell neuroendocrine tumor, and 1 mesothelioma). Thirty-five patients (38.9\%) had documented brain metastases. The median age was 68.5 years (range 36-88), with 70.5 years in the irAEs group and 67.5 years in the non-irAEs group.

Gender was similarly divided in our patient population (41 women, $45.6 \%$, and 49 men, 54.4\%). Seventy-eight patients (86.7\%) received ICIs as monotherapy and 12 $(13.3 \%)$ received ICIs combined with chemotherapy. The median lines of therapy were two (range one to seven lines). The median LOS was 7 days (range 1-37 days). The smoking history of our cohort confirmed 29 never smokers (32.2\%), 50 former smokers (55.6\%), and 11 current smokers (12.2\%). PD-L1 by IHC was reported in 45 patients: 16 (35.6\%) were negative (TPS of $<1 \%), 8(17.8 \%)$ were positive (TPS of $1-49 \%)$, and $21(46.7 \%)$ were highly positive (TPS of $\geq 50 \%$ ). Seventy-seven patients underwent EGFR molecular testing, and 
$20.8 \%(n=16)$ were EGFR positive. The mutational landscape of our patient population is shown in Figure 1.
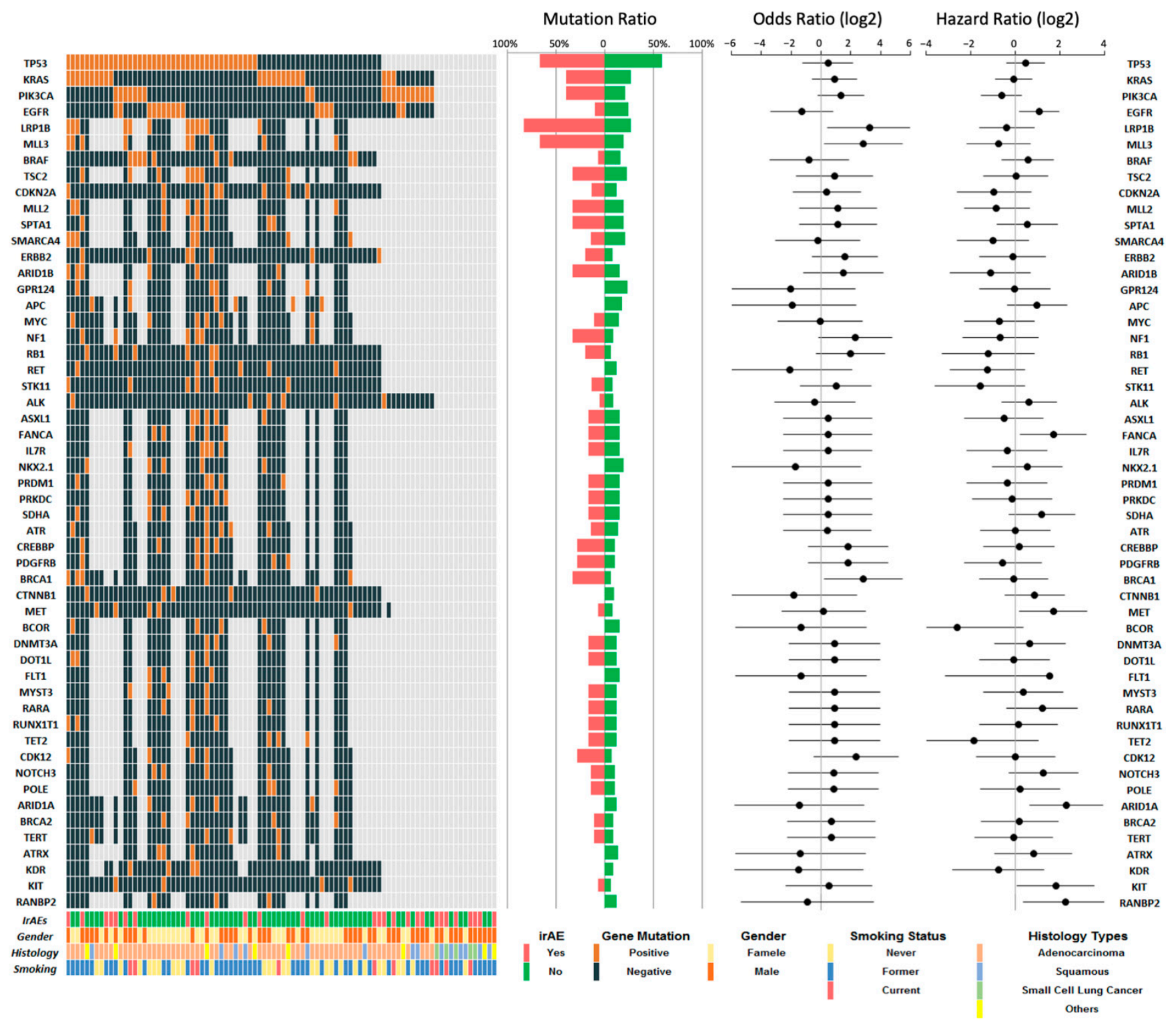

Figure 1. The top detected genomic alterations with OS and irAEs. Oncoplot demonstrating the patient demographic information and top detected genomic alterations in 90 lung cancer patients who were hospitalized during ICI treatment. Mutation rates are shown by patients with irAEs vs. no irAEs. The odds ratios were calculated using univariate logistic regression and hazard ratios with the univariate Cox model. Data visualization and statistical analysis were performed with $R$. 
Table 2. Baseline patient characteristics.

\begin{tabular}{|c|c|c|c|c|}
\hline Characteristics & $n=90(\%)$ & IrAEs $n=28(\%)$ & No $\operatorname{irAEs} n=62(\%)$ & $p$ Values $^{1}$ \\
\hline Median age at ICI (range 36-88) & 68.5 & 70.5 & 67.5 & ns \\
\hline Gender & & & & $<0.05$ \\
\hline Women & $41(45.6 \%)$ & $8(28.6 \%)$ & $33(53.2 \%)$ & \\
\hline Men & $49(54.4 \%)$ & $20(71.4 \%)$ & $29(46.8 \%)$ & \\
\hline Smoking status & & & & $<0.01$ \\
\hline Current & $11(12.2 \%)$ & $6(21.4 \%)$ & $5(8.1 \%)$ & \\
\hline Former & $50(55.6 \%)$ & $19(67.9 \%)$ & $31(50.0 \%)$ & \\
\hline Never & $29(32.2 \%)$ & $3(10.7 \%)$ & $26(41.9 \%)$ & \\
\hline Histology & & & & $<0.01$ \\
\hline Lung adenocarcinoma & $63(70 \%)$ & $16(57.1 \%)$ & $47(75.8 \%)$ & \\
\hline Lung squamous & $14(15.6 \%)$ & $4(14.3 \%)$ & $10(16.1 \%)$ & \\
\hline SCLC & $5(5.6 \%)$ & $5(17.9 \%)$ & 0 & \\
\hline Others $^{2}$ & $8(8.9 \%)$ & $3(10.7 \%)$ & $5(8.1 \%)$ & \\
\hline ICIs with other therapy & & & & ns \\
\hline Yes & $12(13.3 \%)$ & $2(7.1 \%)$ & $10(16.1 \%)$ & \\
\hline No & $78(86.7 \%)$ & $26(92.9 \%)$ & $52(83.9 \%)$ & \\
\hline PD-L1 & & & & ns \\
\hline Negative & $16(17.8 \%)$ & $5(17.9 \%)$ & $11(17.7 \%)$ & \\
\hline $1 \%$ to $<50 \%$ & $8(8.9 \%)$ & $1(3.6 \%)$ & $7(11.3 \%)$ & \\
\hline $50 \%$ and above & $21(23.3 \%)$ & $7(25.0 \%)$ & $14(22.6 \%)$ & \\
\hline Not tested & $45(50.0 \%)$ & $15(53.6 \%)$ & $30(48.4 \%)$ & \\
\hline Median lines of therapy (range 1-7) & 2 & 2 & 2 & ns \\
\hline Brain metastasis & & & & ns \\
\hline Yes & $35(38.9 \%)$ & $10(35.7 \%)$ & $25(40.3 \%)$ & \\
\hline No & $55(61.1 \%)$ & $18(64.3 \%)$ & $37(59.7 \%)$ & \\
\hline Median length of stay (range 1-37) & 7 & 7 & 6 & ns \\
\hline
\end{tabular}

${ }^{1}$ Chi-square test and Fisher's exact test. ns, not significant. ${ }^{2}$ Others: 1 poorly differentiated tumor including NSCLC, not otherwise specified (NSCLC-NOS), 1 large cell lung cancer, 1 lung atypical carcinoid, 1 adenosquamous tumor, 1 mixed large cell with neuroendocrine tumor, 1 small cell transformed lung adenocarcinoma, 1 mixed adenocarcinoma with large cell neuroendocrine tumor, and 1 mesothelioma.

\subsection{Clinical Features in irAEs and Non-irAE Population}

The irAE group comprised more male patients $(n=20,71.4 \%$ vs. $n=29,46.8 \%$; $p<0.05$; Figure 2A), and more current smokers $(n=6,21.4 \%$ vs. $n=5,8.1 \% ; p<0.01$; Figure $2 \mathrm{~B})$ and former smokers $(n=19,67.9 \%$ vs. $n=31,50 \% ; p<0.01$; Figure $2 \mathrm{~B})$. The non-irAE group comprised more never smokers $(n=26,41.9 \%$ vs. $n=3,4.8 \% ; p<0.01$; Figure 2B). Seventeen (60.7\%) patients in the irAE group underwent invasive diagnostic procedures during hospitalization, including bronchoscopy $(n=6,21.4 \%)$, esophageal gastroscopy/colonoscopy $(n=5,17.9 \%)$, thoracentesis $(n=2,7.1 \%)$, liver biopsy $(n=1$, $3.6 \%)$, skin biopsy $(n=1,3.6 \%)$, kidney biopsy $(n=1,3.6 \%)$, and brain surgery $(n=1,3.6 \%)$ as shown in Table 3. In the non-irAE group, 25 (40.3\%) patients underwent thoracentesis $(n=8,12.9 \%)$, bronchoscopy $(n=6,9.7 \%)$, EGD/colonoscopy $(n=6,9.7 \%)$, liver biopsy $(n=3,4.8 \%)$, brain surgery $(n=2,3.2 \%)$, spine surgery $(n=1,1.6 \%)$, and pericardium biopsy $(n=1,1.6 \%)$. 


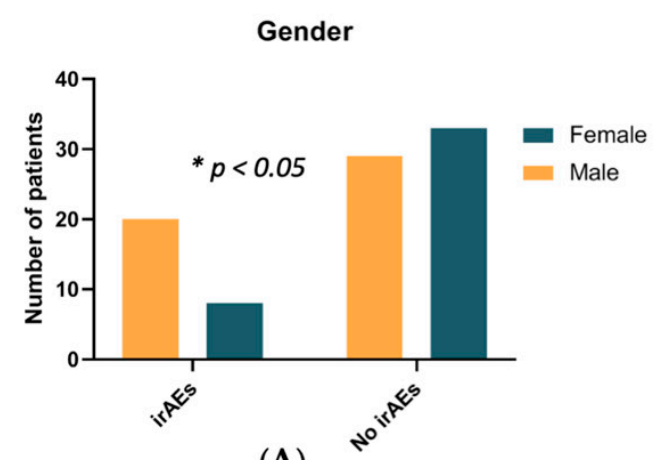

(A)

LRP1B

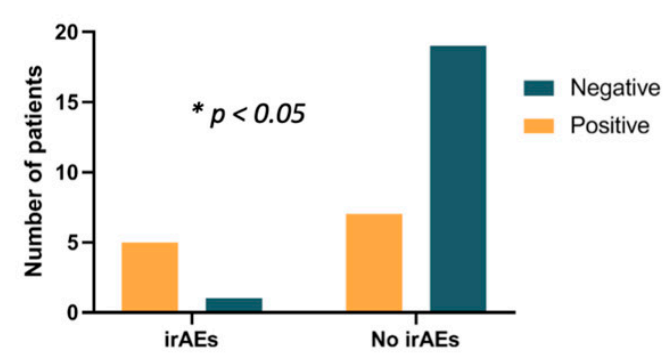

(C)

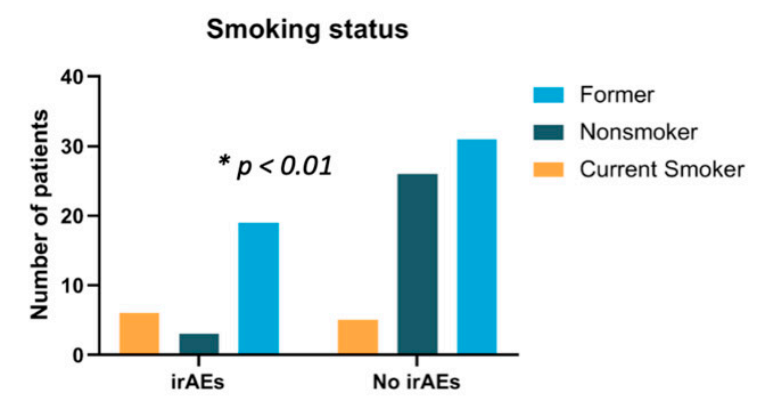

(B)

MLL3

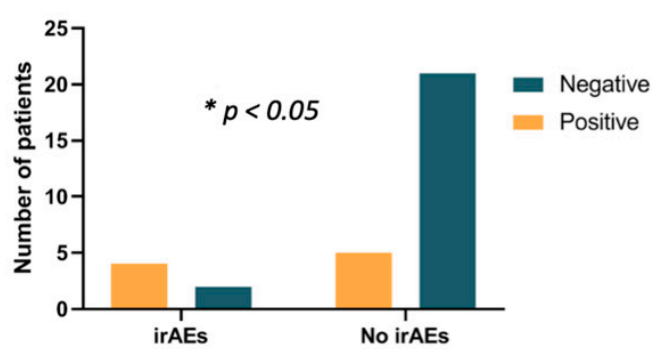

(D)

Figure 2. Significant clinical and molecular features with irAEs. (A) Association of irAEs with gender, (B) smoking status, (C) genomic alterations in $L R P 1 B$, and (D) MLL3. * Fisher's exact test by GraphPad.

Table 3. Invasive procedures after ICIs.

\begin{tabular}{ccc}
\hline Invasive Procedures after ICIs & irAEs $(\boldsymbol{n = 2 8 )}$ & No irAEs $(\boldsymbol{n}=\mathbf{6 2})$ \\
\hline Bronchoscopy/lung biopsy & $6(21.4 \%)$ & $6(9.7 \%)$ \\
EGD/Colonoscopy & $5(17.9 \%)$ & $6(9.7 \%)$ \\
Thoracentesis & $2(7.1 \%)$ & $8(12.9 \%)$ \\
Liver biopsy & $1(3.6 \%)$ & $3(4.8 \%)$ \\
Skin biopsy & $1(3.6 \%)$ & 0 \\
Kidney biopsy & $1(3.6 \%)$ & 0 \\
Brain surgery & $1(3.6 \%)$ & $2(3.2 \%)$ \\
Spine surgery & 0 & $1(1.6 \%)$ \\
Pericardium biopsy & 0 & $1(1.6 \%)$ \\
Total & $17(60.7 \%)$ & $25(40.3 \%)$ \\
\hline
\end{tabular}

${ }^{1}$ Chi-square test $p<0.05$. The total number of patients who had invasive procedures, including one patient who had a lung biopsy, thoracentesis, and pericardium biopsy.

IrAE and non-irAE development were not associated with statistically significant superior OS (Figure 3A). However, we observed a trend toward significance in OS with patients who experienced irAEs compared to those who did not experience irAEs (median 16.4 vs. 6.8 months, $p=0.19$, Figure 3A). A significant OS benefit was confirmed by multivariate analysis for irAE patients $(n=19 / 28,67.9 \%)$ who underwent ICI treatment interruption due to irAE occurrence ( $n=19 / 90,21.1 \%$ vs. $n=71 / 90,78.9 \%$; median 18.5 vs. 6.2 months; $p<0.05$ ) and visualized on survival curves (HR with 95\% CI: 0.47 (0.28-0.79); $p<0.05$; Figure 3B). Patients on the first line of ICI therapy had significantly longer OS than those on second-line or greater ICI therapy $(p<0.01)$. 


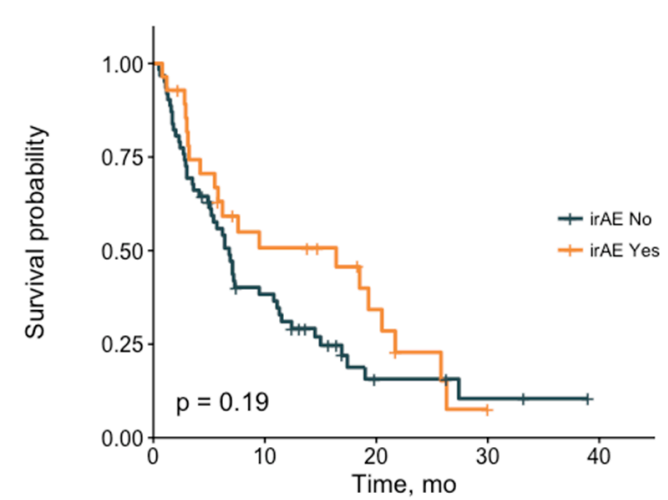

No. at risk

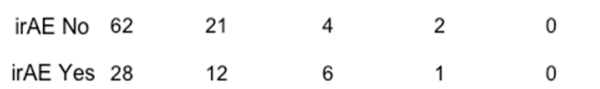

(A)

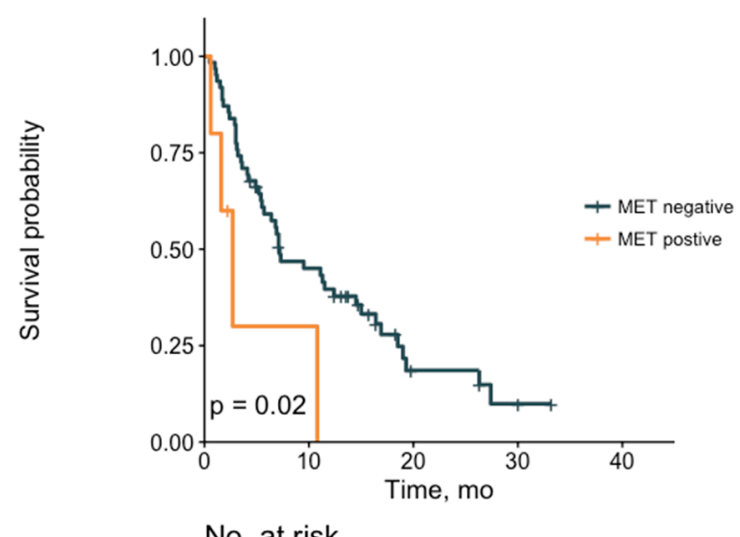

No. at risk

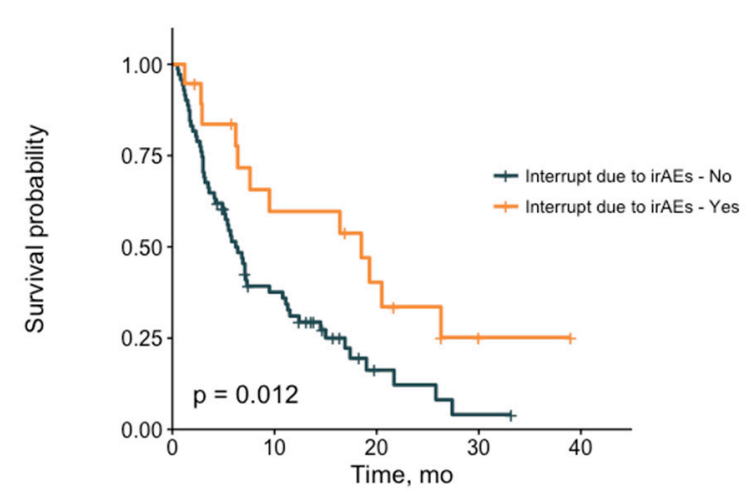

No. at risk

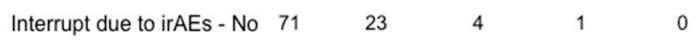

Interrupt due to irAEs - Yes $19 \quad 10 \quad 6 \quad 6 \quad 2 \quad 10$

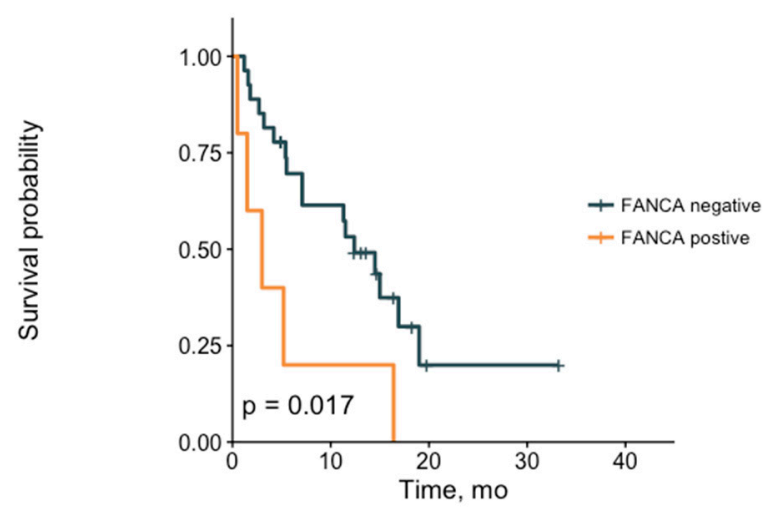

No. at risk

$\begin{array}{ccccc}\text { FANCA negative } & 27 & 15 & 1 & 1 \\ \text { FANCA postive } & 5 & 1 & 0 & 0\end{array}$

(D)

Figure 3. Clinical and molecular features with OS. (A) OS with irAEs, (B) interruption of ICIs due to irAEs, (C) genomic alterations in MET, and (D) FANCA. Log-rank (Mantel-Cox) tests were used to compare the survival curves. Data visualization and statistical analysis were performed with $\mathrm{R}$.

\subsection{Molecular Features in irAE and Non-irAE Population}

In the overall population, TP53 ranked as the most detected GA $(n=40 / 66,60.6 \%)$ followed by LRP1B $(n=12 / 32,37.5 \%), \operatorname{KRAS}(n=23 / 77,29.9 \%), \operatorname{MLL3}(n=9 / 32,28.1 \%)$, $\operatorname{EGFR}(n=16 / 77,20.8 \%)$, and PIK3CA $(n=9 / 66,13.6 \%)$. We analyzed the association between recurrent tumor mutations and irAE occurrence (Table 4). We observed the enrichment of $L R P 1 B$ mutations $(n=5 / 6,83.3 \%$ vs. $n=7 / 26,26.9 \%$; OR $(95 \% \mathrm{CI})=$ 13.5 (1.7-166.1), $p<0.05$; Figure 2C) and MLL3 mutations ( $n=4 / 6,66.7 \%$ vs. $n=5 / 26$, $19.2 \%$; OR $(95 \%$ CI $)=8.4(1.3-49.3), p<0.05$; Figure $2 \mathrm{D})$ in irAE patients compared to non-irAE patients.

However, no statistically significant difference was found in the MLL3 or LRP1B mutation status corresponding with irAE occurrence in our multivariate logistic regression analysis (Table 5). The most frequent GAs and patient demographic information are visualized in the oncoplot in Figure 1. Patients with MET $(n=5 / 67,7.5 \%)$ or FANCA GAs $(n=5 / 32,15.6 \%)$ demonstrated shorter median OS compared to patients without MET (median 2.7 vs. 7.2 months; HR with 95\% CI: $3.1(0.57-17.1), p<0.05)$ or FANCA 
GAs (median 3.0 vs. 12.4 months; HR with 95\% CI: $3.1(0.70-13.8) ; p<0.05)$ (Figure 3D). This relationship between OS and GAs in MET (HR, 3.06; 95\% CI, 1.08-8.65; $p<0.05$ ) and FANCA (HR, 3.31; 95\% CI, 1.22-9.04; $p<0.05)$ was retained in the multivariate Cox analysis (Table 6).

Table 4. Mutations and their associations with irAEs.

\begin{tabular}{|c|c|c|c|c|c|}
\hline Genomics & All (\%) & IrAEs (\%) & No irAEs (\%) & OR $(95 \%$ CI $)$ & $p$ Values $^{1}$ \\
\hline TP53 & & & & & ns \\
\hline Positive & 40 & $10(66.7 \%)$ & $30(58.8 \%)$ & & \\
\hline Negative & 26 & $5(33.3 \%)$ & $21(41.2 \%)$ & & \\
\hline Not tested & 24 & 13 & 11 & & \\
\hline KRAS & & & & & ns \\
\hline Positive & 23 & $8(40 \%)$ & $15(26.3 \%)$ & & \\
\hline Negative & 54 & $12(60 \%)$ & $42(73.7 \%)$ & & \\
\hline Not tested & 13 & 8 & 5 & & \\
\hline EGFR & & & & & ns \\
\hline Positive & 16 & $2(10 \%)$ & $14(24.6 \%)$ & & \\
\hline Negative & 61 & $18(90 \%)$ & $43(75.4 \%)$ & & \\
\hline Not tested & 13 & 8 & 5 & & \\
\hline LRP1B & & & & $13.5(1.7-166.1)$ & $<0.05$ \\
\hline Positive & 12 & $5(83.3 \%)$ & $7(26.9 \%)$ & & \\
\hline Negative & 20 & $1(16.7 \%)$ & $19(73.1 \%)$ & & \\
\hline Not tested & 58 & 22 & 36 & & \\
\hline PIK3CA & & & & & ns \\
\hline Positive & 9 & $3(20 \%)$ & $6(11.8 \%)$ & & \\
\hline Negative & 57 & $12(80 \%)$ & $45(88.2 \%)$ & & \\
\hline Not tested & 24 & 13 & 11 & & \\
\hline MLL3 & & & & $8.4(1.3-49.3)$ & $<0.05$ \\
\hline Positive & 9 & $4(66.7 \%)$ & $5(19.2 \%)$ & & \\
\hline Negative & 23 & $2(33.3 \%)$ & $21(80.8 \%)$ & & \\
\hline Not tested & 58 & 22 & 36 & & \\
\hline TMB & & & & & ns \\
\hline TMB-Low & 5 & $1(33.3 \%)$ & $4(26.7 \%)$ & & \\
\hline $\begin{array}{c}\text { TMB- } \\
\text { Intermediate }\end{array}$ & 9 & $1(33.3 \%)$ & $8(53.3 \%)$ & & \\
\hline TMB-High & 4 & $1(33.3 \%)$ & $3(20 \%)$ & & \\
\hline Not tested & 72 & 25 & 47 & & \\
\hline
\end{tabular}

Table 5. Risk factors for irAEs by multivariate analysis.

\begin{tabular}{ccc}
\hline Risk Factors & Odds Ratio $(\mathbf{9 5 \%}$ CI) & $p$ Values $\mathbf{1}^{\mathbf{1}}$ \\
\hline Gender & References & \\
Female & $1.47(0.43-4.99)$ & 0.5358 \\
Male & & \\
Smoking & References & \\
Never & $3.61(0.43-30.11)$ & 0.2363 \\
Current & $3.44(0.76-15.45)$ & 0.1073 \\
Former & References & \\
MLL3 & $6.52(0.70-60.62)$ & 0.0991 \\
Negative & References & \\
Positive & $8.00(0.65-98.01)$ & 0.1037 \\
LRP1B & \\
Negative & & \\
Positive &
\end{tabular}

${ }^{1}$ Multivariate logistic regression for irAEs by R (excluding small cell lung cancer). 
Table 6. Multivariate analysis for OS $(n=90)$.

\begin{tabular}{|c|c|c|}
\hline Risk Factors & HR $(95 \% C I)$ & $p$ Values $^{1}$ \\
\hline \multicolumn{3}{|l|}{ Gender } \\
\hline Female & Reference & \\
\hline Male & $1.11(0.57-2.15)$ & ns \\
\hline \multicolumn{3}{|l|}{ IrAEs } \\
\hline No & Reference & \\
\hline Yes & $1.21(0.50-2.92)$ & ns \\
\hline \multicolumn{3}{|c|}{ Interrupt ICIs due to irAEs } \\
\hline No & Reference & \\
\hline Yes & $0.05(0.01-0.19)$ & $<0.001$ \\
\hline \multicolumn{3}{|l|}{ Lines of therapy } \\
\hline$\geq 3$ lines & Reference & \\
\hline 2nd line & $0.62(0.25-1.49)$ & \\
\hline 1st line & $0.21(0.07-0.58)$ & $<0.01$ \\
\hline \multicolumn{3}{|l|}{ EGFR } \\
\hline Negative & Reference & \\
\hline Positive & $1.45(0.55-3.77)$ & ns \\
\hline \multicolumn{3}{|l|}{ FANCA } \\
\hline Negative & Reference & \\
\hline Positive & $11.30(3.36-38.01)$ & $<0.001$ \\
\hline \multicolumn{3}{|l|}{ MET } \\
\hline Negative & Reference & \\
\hline Positive & $11.17(2.92-42.81)$ & $<0.001$ \\
\hline
\end{tabular}

${ }^{1}$ Multivariate Cox proportional hazards model for OS (excluding small cell lung cancer).

\section{Discussion}

The use of ICIs in lung cancer treatment has drastically improved the outcomes of advanced NSCLC patients with an average five-year OS of $15.6 \%$ with nivolumab and $23.2 \%$ with pembrolizumab as a first-line therapy [28,29]. However, patients who undergo ICI treatment can experience hospital admissions due to severe irAEs and / or other comorbidities. As researchers continue to investigate ICI treatment in earlier-stage disease, it is necessary to explore strategies in minimizing toxicities and avoiding severe irAEs that could be long-lasting or fatal. In this study, we analyzed 90 patients with thoracic cancers who were hospitalized during ICI treatment. Of those, 28 patients $(31.1 \%)$ experienced irAEs with the most common irAE being pneumonitis ( $n=10 / 90,11.1 \%)$.

This is consistent with other reports demonstrating that $12 \%$ of emergency room visits and inpatient care were associated with irAE development in metastatic solid tumor patients undergoing ICI treatment [30]. This result is also consistent with a previous study that reported immune-related interstitial pneumonia as the most common irAE in $13.2 \%$ $(n=5 / 38)$ of lung cancer patients treated with nivolumab [31].

We also reported that patients with documented irAEs underwent more invasive diagnostic procedures but with no observed difference in the hospital LOS. The severity of irAEs may have caused further intensive interventions due to the risk of long-lasting effects. Sattar et al. described a correlative study between irAEs and efficacy in an older patient population treated with ICIs, and patients age $\geq 75$ years did not present with excess toxicities [32], consistent with our findings of no associations between irAE development and age.

However, we did not observe an OS benefit between our irAE and non-irAE populations. Previous studies have demonstrated superior progression-free survival (PFS) and OS in patients with irAEs, while our study only demonstrated a trend toward significance for OS in our irAE group [31,33-35]. In a large observational study, Grangeon et al. measured the survival outcomes in 270 patients with metastatic NSCLC treated with at least one dose of anti-PD-L1 or anti-PD-1 antibodies. The study stratified cohorts between patients who did and did not experience irAEs. 
Correspondingly, superior PFS and OS were seen in the cohort who experienced irAEs compared to those who did not experience irAEs (OS: not reached (NR) versus (vs) 8.21 months (hazard ratio (HR) 0.29 ; 95\% confidence interval (CI) $0.18-0.46 ; p=0.001$ ); PFS: 5.2 vs. 1.97 months (HR $0.42 ; 95 \%$ CI $0.32-0.57 ; p<0.001)$ ). Interestingly, other measures such as the overall response rate (ORR) $(22.9 \%$ vs. $5.7 \%, p<0.0001)$ and disease control rate (DCR) $(76 \%$ vs. $58 \%, p<0.001)$ were also lengthened in the irAE-positive vs. nonirAE cohorts [36]. In our cohort, we did not observe any survival benefit with the use of corticosteroids.

Interestingly, Haratani et al. showed that patients who required systemic corticosteroids for irAE management had superior survival outcomes, while Shafqat et al. [35]. demonstrated that irAEs were associated with improved PFS regardless of systemic corticosteroids use [35,37]. The 19 patients who had discontinuation or interruption of ICIs due to irAEs had significantly longer OS, which implied the positive correlations of irAEs with survival outcomes. However, in clinical practice, people might be more comfortable to stop treatment when their disease is better-controlled; therefore, this might be a highly selective patient subpopulation.

Our results demonstrated an OS benefit for patients who underwent ICI treatment as first-line compared to second-line or greater $(p<0.01)$. A study by Durbin et al. confirmed our results by showing a shorter OS in metastatic solid tumor patients who underwent ICI treatment as second-line or greater [38]. However, another study also analyzed the safety and efficacy of ICIs as second-line treatment in a real-world setting. Chen et al. described the association between the occurrence of irAEs and higher PFS in a patient population who received ICIs in the second-line setting and concluded that the presence of irAEs may act as a predictive marker for antitumor efficacy [39].

Next, our study revealed that patients who experienced an interruption of ICI treatment due to irAEs had significantly longer OS than those who continued treatment $(p<0.05)$, suggesting a positive correlation between irAE occurrence and survival outcomes. Conversely, Ksienski et al. showed that treatment interruptions in NSCLC patients undergoing treatment with pembrolizumab or nivolumab due to documented irAEs $(n=116 / 271,42.8 \%)$ were associated with a worse OS [40].

A correlative study by Mouri et al. retrospectively analyzed 49 NSCLC patients treated with nivolumab that had treatment interruption due to a serious irAE. With patients stratified into a retreatment or discontinuation cohort, patients rechallenged with nivolumab displayed an ORR of $15 \%$, without a significant increase in irAEs; however, the median OS and PFS did not differ significantly among the patient cohorts [41].

The difference among survival outcomes with varying ICIs used for treatment may also play a role in discontinuation if the patient experiences detrimental irAEs. Lastly, Jia et al. describe varying biomarkers that can predict irAEs based on specific and nonspecific symptoms. Due to irAE effects in every organ, ongoing investigation in regards to the application scope, benefit from treatment interruption, and selection of the treatment population for ICIs based on biomarkers is required [42].

Our analysis reported enrichment of somatic $L R P 1 B$ and MLL3 mutations in patients with irAEs. Yet, it was not statistically significant in the multivariate analysis, likely due to the limited sample size and confounding factors of smoking and gender. $L R P 1 B$ gene encodes for an LDL receptor and acts as a putative tumor suppressor in lung cancer whose function is only partially defined $[43,44]$. Chen et al. reported greater survival and higher TMB in melanoma and NSCLC patients with LRP1B mutations undergoing ICI treatment [45]. MLL3 gene encodes for histone 3 lysine 4 methyltransferases and acts as a tumor suppressor.

Mutated MLL3 (or KMT2C) proteins have been implicated in multiple cancers, including urothelial carcinoma, human lymphoid, and myeloid leukemia [46-48]. Further, we found that NSCLC patients with FANCA mutations had significantly worse OS compared to those without $F A N C A$ mutations. The FANCA gene is important for the repair of double-stranded DNA breaks and is involved in the cellular process known as the Fanconi 
anemia pathway. Outcomes have been assessed in patients treated with ICIs, and the results showed significantly higher objective response rate, longer median PFS, and longer median OS with patients on PD-(L)1 therapy [49].

The survival outcome that we observed was also previously confirmed in a larger cohort by our group, yet further investigation is required [50]. The MET gene encodes a transmembrane receptor tyrosine kinase, and its ligand hepatocyte growth factor (HGF) is involved in the MET/HGF signaling pathway. Patients in our cohort with MET GAs were associated with poor OS, and the statistical significance was retained in the multivariate analysis.

This is consistent with the previous findings of MET mutated lung cancer and worsened outcomes with immunotherapy treatment [24,51]. We did not observe a correlation between TMB with irAEs or OS, which may be explained by the lack of TMB information in our cohort as only 18 patients had TMB information available. It is unclear how somatic mutations in tumors contribute to the development of irAEs, and more research is warranted to examine the role of genomic mutations in lung cancer immunotherapy.

\section{Conclusions}

Our retrospective analysis investigated the clinical and molecular features of lung cancer patients undergoing ICI treatment who were hospitalized. We observed that patients with irAE occurrences who required treatment interruption had a significantly longer OS. Further, patients with somatic GAs in FANCA and MET had a worse OS, which is consistent with previously reported studies. A limitation of this study is that the patient cohort was of limited sample size and from a single institution. Further investigation is required to analyze a larger and diverse population set. Strikingly, our findings indicated that the majority of patients who were hospitalized on ICI treatment did not have an irAE. Therefore, future clinical studies should focus on identifying and cataloging the variables that may be associated with hospitalization due to ICI treatment.

Author Contributions: Conceptualization, D.Z., H.L., I.M., E.M., M.K., K.L.R., K.M., and R.S.; Data curation, D.Z., I.M., C.C., R.P., J.F., A.R.B., and Y.X.; Formal analysis, D.Z., H.L., I.M., C.C., E.M., M.K., K.L.R., K.M., and R.S.; Funding acquisition, D.Z. and R.S.; Investigation, D.Z., H.L., I.M., C.C., R.P., J.F., A.R.B., P.K., Y.X., E.M., M.K., K.L.R., K.M., and R.S.; Methodology, D.Z., H.L., I.M., C.C., R.P., J.F., A.R.B., P.K., Y.X., E.M., M.K., K.L.R., K.M., and R.S.; Project administration, P.K. and R.S.; Resources, R.S.; Software, H.L.; Supervision, P.K. and R.S.; Validation, D.Z., H.L., I.M., C.C., R.P., J.F., A.R.B., P.K., Y.X., E.M., M.K., K.L.R., K.M., and R.S.; Visualization, D.Z., H.L., I.M., and C.C.; Roles/Writing—original draft, D.Z., H.L., I.M., and R.S.; Writing—review \& editing, D.Z., H.L., I.M., C.C., R.P., J.F., A.R.B., P.K., Y.X., E.M., M.K., K.L.R., K.M., and R.S.; All authors have read and agreed to the published version of the manuscript.

Funding: This work was supported by the National Cancer Institute of the National Institutes of Health under awards numbers P30CA033572 and U54CA209978.

Institutional Review Board Statement: The study was conducted according to the guidelines of the Declaration of Helsinki, and approved by the Institutional Review Board of City of Hope (IRB \#18529; 12/20/2019).

Informed Consent Statement: Patient consent was waived per IRB requirements since it was a retrospective observational study.

Data Availability Statement: The data presented in this study are available on request from the corresponding author.

Acknowledgments: We thank the Thoracic Disease Team, Department of Medical Oncology, and Center for Clinical Informatics at City of Hope for their help in this analysis.

Conflicts of Interest: The authors declare that they have no competing interest relevant to this work. 


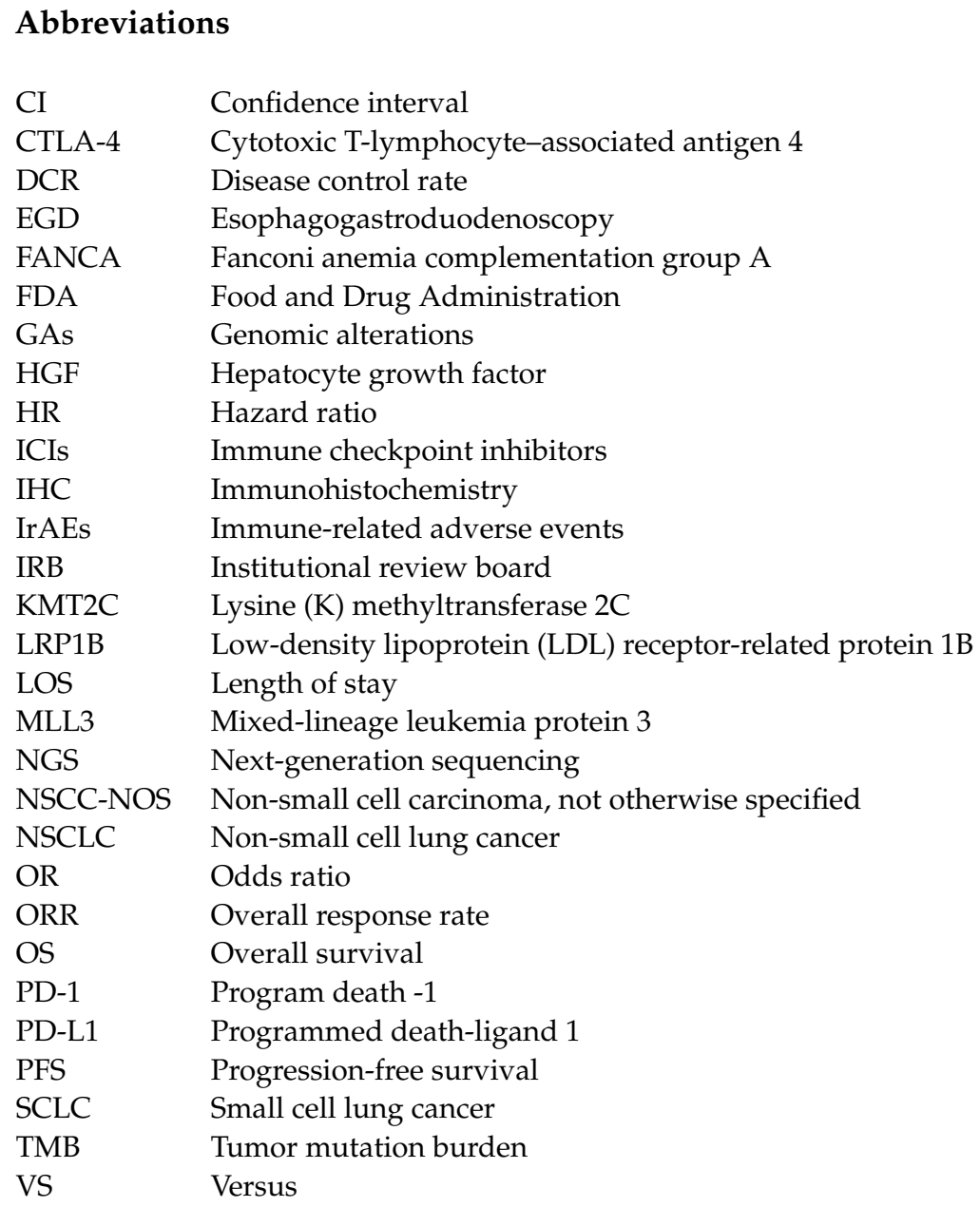

\section{References}

1. Mok, T.S.K.; Wu, Y.L.; Kudaba, I.; Kowalski, D.M.; Cho, B.C.; Turna, H.Z.; Castro, G., Jr.; Srimuninnimit, V.; Laktionov, K.K.; Bondarenko, I.; et al. Pembrolizumab versus chemotherapy for previously untreated, PD-L1-expressing, locally advanced or metastatic non-small-cell lung cancer (KEYNOTE-042): A randomised, open-label, controlled, phase 3 trial. Lancet 2019, 393, 1819-1830. [CrossRef]

2. Gandhi, L.; Rodriguez-Abreu, D.; Gadgeel, S.; Esteban, E.; Felip, E.; De Angelis, F.; Domine, M.; Clingan, P.; Hochmair, M.J.; Powell, S.F.; et al. Pembrolizumab plus Chemotherapy in Metastatic Non-Small-Cell Lung Cancer. N. Engl. J. Med. 2018, 378, 2078-2092. [CrossRef] [PubMed]

3. Paz-Ares, L.; Luft, A.; Vicente, D.; Tafreshi, A.; Gumus, M.; Mazieres, J.; Hermes, B.; Cay Senler, F.; Csoszi, T.; Fulop, A.; et al. Pembrolizumab plus Chemotherapy for Squamous Non-Small-Cell Lung Cancer. N. Engl. J. Med. 2018, 379, 2040-2051. [CrossRef]

4. $\quad$ Reck, M.; Rodríguez-Abreu, D.; Robinson, A.G.; Hui, R.; Csőszi, T.; Fülöp, A.; Gottfried, M.; Peled, N.; Tafreshi, A.; Cuffe, S.; et al. Pembrolizumab versus chemotherapy for PD-L1-positive non-small-cell lung cancer. N. Engl. J. Med. 2016, 375, 1823-1833. [CrossRef] [PubMed]

5. Horn, L.; Mansfield, A.S.; Szczesna, A.; Havel, L.; Krzakowski, M.; Hochmair, M.J.; Huemer, F.; Losonczy, G.; Johnson, M.L.; Nishio, M.; et al. First-Line Atezolizumab plus Chemotherapy in Extensive-Stage Small-Cell Lung Cancer. N. Engl. J. Med. 2018, 379, 2220-2229. [CrossRef]

6. Socinski, M.A.; Jotte, R.M.; Cappuzzo, F.; Orlandi, F.; Stroyakovskiy, D.; Nogami, N.; Rodriguez-Abreu, D.; Moro-Sibilot, D.; Thomas, C.A.; Barlesi, F.; et al. Atezolizumab for First-Line Treatment of Metastatic Nonsquamous NSCLC. N. Engl. J. Med. 2018, 378, 2288-2301. [CrossRef]

7. Paz-Ares, L.; Dvorkin, M.; Chen, Y.; Reinmuth, N.; Hotta, K.; Trukhin, D.; Statsenko, G.; Hochmair, M.J.; Özgüroğlu, M.; Ji, J.H.; et al. Durvalumab plus platinum-etoposide versus platinum-etoposide in first-line treatment of extensive-stage small-cell lung cancer (CASPIAN): A randomised, controlled, open-label, phase 3 trial. Lancet 2019, 394, 1929-1939. [CrossRef]

8. Antonia, S.J.; Lopez-Martin, J.A.; Bendell, J.; Ott, P.A.; Taylor, M.; Eder, J.P.; Jager, D.; Pietanza, M.C.; Le, D.T.; de Braud, F.; et al. Nivolumab alone and nivolumab plus ipilimumab in recurrent small-cell lung cancer (CheckMate 032): A multicentre, open-label, phase 1/2 trial. Lancet Oncol. 2016, 17, 883-895. [CrossRef] 
9. $\quad$ Brahmer, J.; Reckamp, K.L.; Baas, P.; Crino, L.; Eberhardt, W.E.; Poddubskaya, E.; Antonia, S.; Pluzanski, A.; Vokes, E.E.; Holgado, E.; et al. Nivolumab versus Docetaxel in Advanced Squamous-Cell Non-Small-Cell Lung Cancer. N. Engl. J. Med. 2015, 373, 123-135. [CrossRef]

10. Brahmer, J.R.; Govindan, R.; Anders, R.A.; Antonia, S.J.; Sagorsky, S.; Davies, M.J.; Dubinett, S.M.; Ferris, A.; Gandhi, L.; Garon, E.B.; et al. The Society for Immunotherapy of Cancer consensus statement on immunotherapy for the treatment of non-small cell lung cancer (NSCLC). J. Immunother. Cancer 2018, 6, 75. [CrossRef]

11. Hellmann, M.D.; Paz-Ares, L.; Bernabe Caro, R.; Zurawski, B.; Kim, S.-W.; Carcereny Costa, E.; Park, K.; Alexandru, A.; Lupinacci, L.; de la Mora Jimenez, E.; et al. Nivolumab plus Ipilimumab in Advanced Non,Äîsmall-Cell Lung Cancer. N. Engl. J. Med. 2019, 381, 2020-2031. [CrossRef] [PubMed]

12. Reck, M.; Ciuleanu, T.-E.; Dols, M.C.; Schenker, M.; Zurawski, B.; Menezes, J.; Richardet, E.; Bennouna, J.; Felip, E.; Juan-Vidal, O.; et al. Nivolumab (NIVO) + ipilimumab (IPI) + 2 cycles of platinum-doublet chemotherapy (chemo) vs. 4 cycles chemo as first-line (1L) treatment (tx) for stage IV/recurrent non-small cell lung cancer (NSCLC): CheckMate 9LA. J. Clin. Oncol. 2020, 38, 9501. [CrossRef]

13. Antonia, S.J.; Villegas, A.; Daniel, D.; Vicente, D.; Murakami, S.; Hui, R.; Yokoi, T.; Chiappori, A.; Lee, K.H.; de Wit, M.; et al. Durvalumab after Chemoradiotherapy in Stage III Non-Small-Cell Lung Cancer. N. Engl. J. Med. 2017, 377, 1919-1929. [CrossRef]

14. Forde, P.M.; Chaft, J.E.; Smith, K.N.; Anagnostou, V.; Cottrell, T.R.; Hellmann, M.D.; Zahurak, M.; Yang, S.C.; Jones, D.R.; Broderick, S.; et al. Neoadjuvant PD-1 Blockade in Resectable Lung Cancer. N. Engl. J. Med. 2018, 378, 1976-1986. [CrossRef] [PubMed]

15. Postow, M.A.; Sidlow, R.; Hellmann, M.D. Immune-Related Adverse Events Associated with Immune Checkpoint Blockade. N. Engl. J. Med. 2018, 378, 158-168. [CrossRef] [PubMed]

16. Weber, J.S.; Kahler, K.C.; Hauschild, A. Management of immune-related adverse events and kinetics of response with ipilimumab. J. Clin. Oncol. 2012, 30, 2691-2697. [CrossRef]

17. Arnaud-Coffin, P.; Maillet, D.; Gan, H.K.; Stelmes, J.J.; You, B.; Dalle, S.; Peron, J. A systematic review of adverse events in randomized trials assessing immune checkpoint inhibitors. Int. J. Cancer 2019, 145, 639-648. [CrossRef]

18. Wang, D.Y.; Salem, J.E.; Cohen, J.V.; Chandra, S.; Menzer, C.; Ye, F.; Zhao, S.; Das, S.; Beckermann, K.E.; Ha, L.; et al. Fatal Toxic Effects Associated With Immune Checkpoint Inhibitors: A Systematic Review and Meta-analysis. JAMA Oncol. 2018, 4, 1721-1728. [CrossRef]

19. Thompson, J.A.; Schneider, B.J.; Brahmer, J.; Andrews, S.; Armand, P.; Bhatia, S.; Budde, L.E.; Costa, L.; Davies, M.; Dunnington, D.; et al. Management of Immunotherapy-Related Toxicities, Version 1.2019. J. Natl. Compr. Cancer Netw. 2019, 17, 255-289. [CrossRef]

20. Puzanov, I.; Diab, A.; Abdallah, K.; Bingham, C.O., 3rd; Brogdon, C.; Dadu, R.; Hamad, L.; Kim, S.; Lacouture, M.E.; LeBoeuf, N.R.; et al. Managing toxicities associated with immune checkpoint inhibitors: Consensus recommendations from the Society for Immunotherapy of Cancer (SITC) Toxicity Management Working Group. J. Immunother. Cancer 2017, 5, 95. [CrossRef]

21. Brahmer, J.R.; Lacchetti, C.; Schneider, B.J.; Atkins, M.B.; Brassil, K.J.; Caterino, J.M.; Chau, I.; Ernstoff, M.S.; Gardner, J.M.; Ginex, P.; et al. Management of Immune-Related Adverse Events in Patients Treated With Immune Checkpoint Inhibitor Therapy: American Society of Clinical Oncology Clinical Practice Guideline. J. Clin. Oncol. 2018, 36, 1714-1768. [CrossRef]

22. Hellmann, M.D.; Nathanson, T.; Rizvi, H.; Creelan, B.C.; Sanchez-Vega, F.; Ahuja, A.; Ni, A.; Novik, J.B.; Mangarin, L.M.B.; Abu-Akeel, M.; et al. Genomic Features of Response to Combination Immunotherapy in Patients with Advanced Non-Small-Cell Lung Cancer. Cancer Cell 2018, 33, 843-852.e4. [CrossRef]

23. Skoulidis, F.; Goldberg, M.E.; Greenawalt, D.M.; Hellmann, M.D.; Awad, M.M.; Gainor, J.F.; Schrock, A.B.; Hartmaier, R.J.; Trabucco, S.E.; Gay, L.; et al. STK11/LKB1 Mutations and PD-1 Inhibitor Resistance in KRAS-Mutant Lung Adenocarcinoma. Cancer Discov. 2018, 8, 822-835. [CrossRef]

24. Mazieres, J.; Drilon, A.; Lusque, A.; Mhanna, L.; Cortot, A.B.; Mezquita, L.; Thai, A.A.; Mascaux, C.; Couraud, S.; Veillon, R.; et al. Immune checkpoint inhibitors for patients with advanced lung cancer and oncogenic driver alterations: Results from the IMMUNOTARGET registry. Ann. Oncol. 2019, 30, 1321-1328. [CrossRef]

25. Schoenfeld, A.J.; Arbour, K.C.; Rizvi, H.; Iqbal, A.N.; Gadgeel, S.M.; Girshman, J.; Kris, M.G.; Riely, G.J.; Yu, H.A.; Hellmann, M.D. Severe immune-related adverse events are common with sequential PD-(L)1 blockade and osimertinib. Ann. Oncol. 2019, 30, 839-844. [CrossRef] [PubMed]

26. June, C.H.; Warshauer, J.T.; Bluestone, J.A. Is autoimmunity the Achilles' heel of cancer immunotherapy? Nat. Med. 2017, 23, 540-547. [CrossRef] [PubMed]

27. R Core Team. R: A Language and Environment for Statistical Computing; R Core Team: Vienna, Austria, 2019.

28. Garon, E.B.; Hellmann, M.D.; Rizvi, N.A.; Carcereny, E.; Leighl, N.B.; Ahn, M.J.; Eder, J.P.; Balmanoukian, A.S.; Aggarwal, C.; Horn, L.; et al. Five-Year Overall Survival for Patients With Advanced NonSmall-Cell Lung Cancer Treated With Pembrolizumab: Results From the Phase I KEYNOTE-001 Study. J. Clin. Oncol. 2019, 37, 2518. [CrossRef] [PubMed]

29. Topalian, S.L.; Hodi, F.S.; Brahmer, J.R.; Gettinger, S.N.; Smith, D.C.; McDermott, D.F.; Powderly, J.D.; Sosman, J.A.; Atkins, M.B.; Leming, P.D.; et al. Five-Year Survival and Correlates Among Patients With Advanced Melanoma, Renal Cell Carcinoma, or Non-Small Cell Lung Cancer Treated With Nivolumab. JAMA Oncol. 2019, 5, 1411-1420. [CrossRef]

30. Parikh, A.B.; Zhong, X.; Mellgard, G.; Qin, Q.; Patel, V.G.; Wang, B.; Alerasool, P.; Garcia, P.; Leiter, A.; Gallagher, E.J.; et al. Risk Factors for Emergency Room and Hospital Care Among Patients With Solid Tumors on Immune Checkpoint Inhibitor Therapy. Am. J. Clin. Oncol. 2021, 44, 114-120. [CrossRef] 
31. Sato, K.; Akamatsu, H.; Murakami, E.; Sasaki, S.; Kanai, K.; Hayata, A.; Tokudome, N.; Akamatsu, K.; Koh, Y.; Ueda, H.; et al. Correlation between immune-related adverse events and efficacy in non-small cell lung cancer treated with nivolumab. Lung Cancer 2018, 115, 71-74. [CrossRef]

32. Sattar, J.; Kartolo, A.; Hopman, W.M.; Lakoff, J.M.; Baetz, T. The efficacy and toxicity of immune checkpoint inhibitors in a real-world older patient population. J. Geriatr. Oncol. 2018. [CrossRef]

33. Ricciuti, B.; Genova, C.; De Giglio, A.; Bassanelli, M.; Dal Bello, M.G.; Metro, G.; Brambilla, M.; Baglivo, S.; Grossi, F.; Chiari, R. Impact of immune-related adverse events on survival in patients with advanced non-small cell lung cancer treated with nivolumab: Long-term outcomes from a multi-institutional analysis. J. Cancer Res. Clin. Oncol. 2019, 145, 479-485. [CrossRef]

34. Ahn, B.C.; Pyo, K.H.; Xin, C.F.; Jung, D.; Shim, H.S.; Lee, C.Y.; Park, S.Y.; Yoon, H.I.; Hong, M.H.; Cho, B.C.; et al. Comprehensive analysis of the characteristics and treatment outcomes of patients with non-small cell lung cancer treated with anti-PD-1 therapy in real-world practice. J. Cancer Res. Clin. Oncol. 2019, 145, 1613-1623. [CrossRef]

35. Haratani, K.; Hayashi, H.; Chiba, Y.; Kudo, K.; Yonesaka, K.; Kato, R.; Kaneda, H.; Hasegawa, Y.; Tanaka, K.; Takeda, M.; et al. Association of Immune-Related Adverse Events With Nivolumab Efficacy in Non-Small-Cell Lung Cancer. JAMA Oncol. 2018, 4, 374-378. [CrossRef]

36. Grangeon, M.; Tomasini, P.; Chaleat, S.; Jeanson, A.; Souquet-Bressand, M.; Khobta, N.; Bermudez, J.; Trigui, Y.; Greillier, L.; Blanchon, M.; et al. Association Between Immune-related Adverse Events and Efficacy of Immune Checkpoint Inhibitors in Non-small-cell Lung Cancer. Clin. Lung Cancer 2019, 20, 201-207. [CrossRef] [PubMed]

37. Shafqat, H.; Gourdin, T.; Sion, A. Immune-related adverse events are linked with improved progression-free survival in patients receiving anti-PD-1/PD-L1 therapy. Semin. Oncol. 2018, 45, 156-163. [CrossRef] [PubMed]

38. Durbin, S.M.; Zubiri, L.; Niemierko, A.; Bardia, A.; Sullivan, R.J.; McEwen, C.; Mulvey, T.M.; Allen, I.M.; Lawrence, D.P.; Cohen, J.V.; et al. Clinical Outcomes of Patients with Metastatic Cancer Receiving Immune Checkpoint Inhibitors in the Inpatient Setting. Oncologist 2021, 26, 49-55. [CrossRef]

39. Chen, M.; Li, Q.; Xu, Y.; Zhao, J.; Zhang, L.; Wei, L.; Zhong, W.; Wang, M. Immunotherapy as second-line treatment and beyond for non-small cell lung cancer in a single center of China: Outcomes, toxicities, and clinical predictive factors from a real-world retrospective analysis. Thorac. Cancer 2020, 11, 1955-1962. [CrossRef]

40. Ksienski, D.; Wai, E.S.; Croteau, N.; Fiorino, L.; Brooks, E.; Poonja, Z.; Fenton, D.; Geller, G.; Glick, D.; Lesperance, M. Efficacy of Nivolumab and Pembrolizumab in Patients With Advanced Non-Small-Cell Lung Cancer Needing Treatment Interruption Because of Adverse Events: A Retrospective Multicenter Analysis. Clin. Lung Cancer 2019, 20, e97-e106. [CrossRef] [PubMed]

41. Mouri, A.; Kaira, K.; Yamaguchi, O.; Shiono, A.; Miura, Y.; Hashimoto, K.; Nishihara, F.; Murayama, Y.; Kobayashi, K.; Kagamu, H. Clinical difference between discontinuation and retreatment with nivolumab after immune-related adverse events in patients with lung cancer. Cancer Chemother. Pharmacol. 2019, 84, 873-880. [CrossRef] [PubMed]

42. Jia, X.-H.; Geng, L.-Y.; Jiang, P.-P.; Xu, H.; Nan, K.-J.; Yao, Y.; Jiang, L.-L.; Sun, H.; Qin, T.-J.; Guo, H. The biomarkers related to immune related adverse events caused by immune checkpoint inhibitors. J. Exp. Clin. Cancer Res. 2020, 39, 284. [CrossRef] [PubMed]

43. Beer, A.G.; Zenzmaier, C.; Schreinlechner, M.; Haas, J.; Dietrich, M.F.; Herz, J.; Marschang, P. Expression of a recombinant full-length LRP1B receptor in human non-small cell lung cancer cells confirms the postulated growth-suppressing function of this large LDL receptor family member. Oncotarget 2016, 7, 68721-68733. [CrossRef] [PubMed]

44. Liu, C.X.; Musco, S.; Lisitsina, N.M.; Yaklichkin, S.Y.; Lisitsyn, N.A. Genomic organization of a new candidate tumor suppressor gene, LRP1B. Genomics 2000, 69, 271-274. [CrossRef]

45. Chen, H.; Chong, W.; Wu, Q.; Yao, Y.; Mao, M.; Wang, X. Association of LRP1B Mutation With Tumor Mutation Burden and Outcomes in Melanoma and Non-small Cell Lung Cancer Patients Treated With Immune Check-Point Blockades. Front. Immunol. 2019, 10, 1113. [CrossRef] [PubMed]

46. Fountzilas, E.; Kotoula, V.; Koliou, G.A.; Giannoulatou, E.; Gogas, H.; Papadimitriou, C.; Tikas, I.; Zhang, J.; Papadopoulou, K.; Zagouri, F.; et al. Pathogenic mutations and overall survival in 3,084 patients with cancer: The Hellenic Cooperative Oncology Group Precision Medicine Initiative. Oncotarget 2020, 11, 1-14. [CrossRef] [PubMed]

47. Chen, C.; Liu, Y.; Rappaport, A.R.; Kitzing, T.; Schultz, N.; Zhao, Z.; Shroff, A.S.; Dickins, R.A.; Vakoc, C.R.; Bradner, J.E.; et al. MLL3 is a haploinsufficient 7q tumor suppressor in acute myeloid leukemia. Cancer Cell 2014, 25, 652-665. [CrossRef]

48. Rampias, T.; Karagiannis, D.; Avgeris, M.; Polyzos, A.; Kokkalis, A.; Kanaki, Z.; Kousidou, E.; Tzetis, M.; Kanavakis, E.; Stravodimos, K.; et al. The lysine-specific methyltransferase KMT2C/MLL3 regulates DNA repair components in cancer. EMBO Rep. 2019, 20. [CrossRef] [PubMed]

49. Ricciuti, B.; Recondo, G.; Spurr, L.F.; Li, Y.Y.; Lamberti, G.; Venkatraman, D.; Umeton, R.; Cherniack, A.D.; Nishino, M.; Sholl, L.M.; et al. Impact of DNA Damage Response and Repair (DDR) Gene Mutations on Efficacy of PD-(L)1 Immune Checkpoint Inhibition in Non-Small Cell Lung Cancer. Clin. Cancer Res. 2020, 26, 4135-4142. [CrossRef] [PubMed]

50. Zhao, D.; Mambetsariev, I.; Li, H.; Chen, C.; Fricke, J.; Fann, P.; Kulkarni, P.; Xing, Y.; Lee, P.P.; Bild, A.; et al. Association of molecular characteristics with survival in advanced non-small cell lung cancer patients treated with checkpoint inhibitors. Lung Cancer 2020, 146, 174-181. [CrossRef]

51. Sabari, J.K.; Leonardi, G.C.; Shu, C.A.; Umeton, R.; Montecalvo, J.; Ni, A.; Chen, R.; Dienstag, J.; Mrad, C.; Bergagnini, I.; et al. PD-L1 expression, tumor mutational burden, and response to immunotherapy in patients with MET exon 14 altered lung cancers. Ann. Oncol. 2018, 29, 2085-2091. [CrossRef] 